\title{
Improved electrical transport in Al-doped zinc oxide by thermal treatment
}

F. Ruske, M. Roczen, K. Lee, M. Wimmer, S. Gall, J. Hüpkes, D. Hrunski, and B. Rech

Citation: Journal of Applied Physics 107, 013708 (2010);

View online: https://doi.org/10.1063/1.3269721

View Table of Contents: http://aip.scitation.org/toc/jap/107/1

Published by the American Institute of Physics

\section{Articles you may be interested in}

A comprehensive review of $\mathrm{ZnO}$ materials and devices

Journal of Applied Physics 98, 041301 (2005); 10.1063/1.1992666

Aluminum-doped zinc oxide films as transparent conductive electrode for organic light-emitting devices Applied Physics Letters 83, 1875 (2003); 10.1063/1.1605805

Structural, electrical and optical properties of aluminum doped zinc oxide films prepared by radio frequency magnetron sputtering

Journal of Applied Physics 81, 7764 (1998); 10.1063/1.365556

Transparent conducting aluminum-doped zinc oxide thin films for organic light-emitting devices

Applied Physics Letters 76, 259 (2000); 10.1063/1.125740

Efforts to improve carrier mobility in radio frequency sputtered aluminum doped zinc oxide films Journal of Applied Physics 95, 1911 (2004); 10.1063/1.1641524

The effect of front $\mathrm{ZnO}: \mathrm{Al}$ surface texture and optical transparency on efficient light trapping in silicon thin-film solar cells

Journal of Applied Physics 101, 074903 (2007); 10.1063/1.2715554

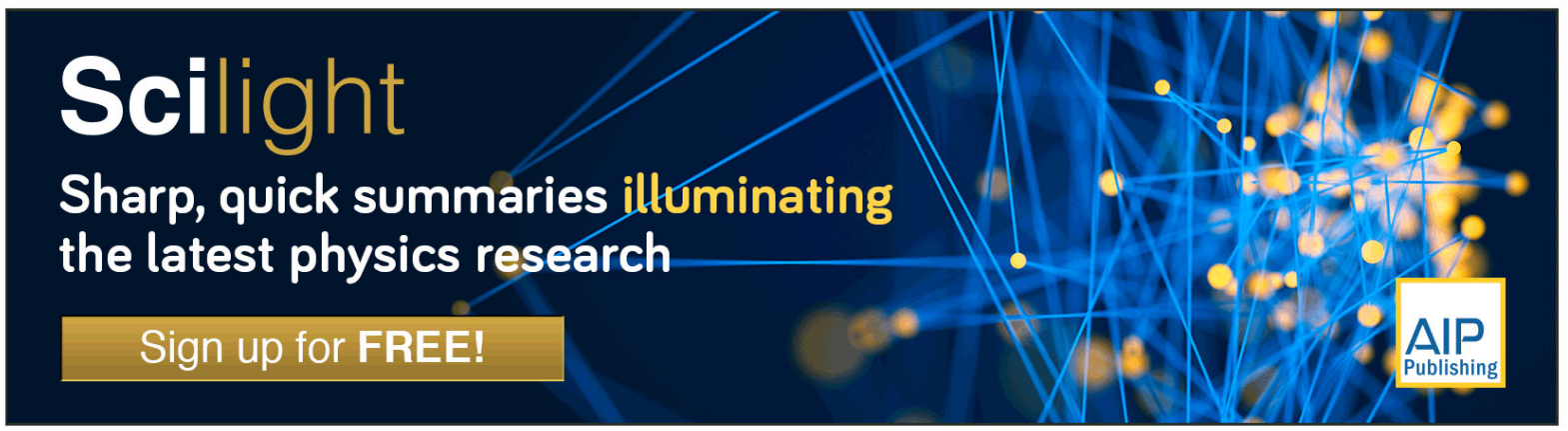




\title{
Improved electrical transport in Al-doped zinc oxide by thermal treatment
}

\author{
F. Ruske, ${ }^{1, a)}$ M. Roczen, ${ }^{1}$ K. Lee, ${ }^{1}$ M. Wimmer, ${ }^{1}$ S. Gall, ${ }^{1}$ J. Hüpkes,${ }^{2}$ D. Hrunski, ${ }^{2}$ and \\ B. Rech ${ }^{1}$ \\ ${ }^{1}$ Institute of Silicon Photovoltaics, Helmholtz-Zentrum Berlin für Materialien und Energie, Kekuléstraße 5, \\ 12489 Berlin, Germany \\ ${ }^{2}$ Institut für Energieforschung-Photovoltaik, Forschungszentrum Jülich, 52425 Jülich, Germany
}

(Received 22 August 2009; accepted 6 November 2009; published online 8 January 2010)

\begin{abstract}
A postdeposition thermal treatment has been applied to sputtered Al-doped zinc oxide films and shown to strongly decrease the resistivity of the films. While high temperature annealing usually leads to deterioration of electrical transport properties, a silicon capping layer successfully prevented the degradation of carrier concentration during the annealing step. The effect of annealing time and temperature has been studied in detail. A mobility increase from values of around $40 \mathrm{~cm}^{2} / \mathrm{Vs}$ up to $67 \mathrm{~cm}^{2} / \mathrm{Vs}$, resulting in a resistivity of $1.4 \times 10^{-4} \Omega \mathrm{cm}$ has been obtained for annealing at temperatures of $650{ }^{\circ} \mathrm{C}$. The high mobility increase is most likely obtained by reduced grain boundary scattering. Changes in carrier concentration in the films caused by the thermal treatment are the result of two competing processes. For short annealing procedures we observed an increase in carrier concentration that we attribute to hydrogen diffusing into the zinc oxide film from a silicon nitride barrier layer between the zinc oxide and the glass substrate and the silicon capping layer on top of the zinc oxide. Both are hydrogen-rich if deposited by plasma-enhanced chemical vapor deposition. For longer annealing times a decrease in carrier concentration can occur if a thin capping layer is used. This can be explained by the deteriorating effect of oxygen during thermal treatments which is well known from annealing of uncapped zinc oxide films. The reduction in carrier concentration can be prevented by the use of capping layers with thicknesses of $40 \mathrm{~nm}$ or more. (C) 2010 American Institute of Physics. [doi:10.1063/1.3269721]
\end{abstract}

\section{INTRODUCTION}

Highly doped zinc oxide films are a prominent example of a transparent and conducting oxide (TCO) material. The research on TCO materials is driven by the wide range of possible applications of TCO films in many optoelectronic devices. ${ }^{1-3}$ Among the various applications, thin film photovoltaics is a main driver for material research and deposition process development of TCO materials.

In the case of silicon-based thin film photovoltaics, tandem solar cells with a bottom cell made of hydrogenated microcrystalline silicon $(\mu \mathrm{c}-\mathrm{Si}: \mathrm{H})$ are already being produced. Microcrystalline silicon has a similar absorption behavior to crystalline silicon and thus can absorb light up to $1100 \mathrm{~nm}$. This also has a severe demand on the TCO front contact, as a high optical transmission is required up to this wavelength. This means that a minimization of resistivity of the TCO layer cannot be carried out by maximizing the carrier concentration in the films, as high doping levels lead to a low plasma wavelength and thus to absorption in the near infrared (NIR) wavelength region. A maximization of mobility is favored instead and thus this is a key research topic in the development of high quality TCO films.

High efficiency solar cells have been prepared on various TCO substrates. Zinc oxide films used in this context are either produced by low pressure chemical vapor deposition (LPCVD) (Ref. 4) or magnetron sputtering. At present the best $\mu \mathrm{c}-\mathrm{Si}: \mathrm{H}$ solar cells on sputtered $\mathrm{ZnO}$ films are achieved

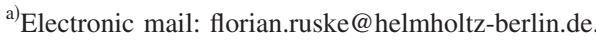

on RF sputtered $\mathrm{ZnO}$ :Al films that undergo a chemical etching procedure for texturing the film surface. The resulting roughness leads to strong light scattering that causes trapping of light in the absorber layer, thus increasing the current collection in the long wavelength region. ${ }^{5}$ In the as-deposited state the mobilities of these films reach up to $\sim 45 \mathrm{~cm}^{2} / \mathrm{Vs}^{6}$

As an alternative to $\mu \mathrm{c}-\mathrm{Si}: \mathrm{H}$, polycrystalline silicon (poly-Si) films can used as absorber layers in thin film solar cells. Single-junction efficiencies above $10 \%$ have already been reported ${ }^{7}$ and an adaptation of the formation process to a substrate configuration including a TCO front contact is being worked on. ${ }^{8}$ In this approach the poly-Si layers are formed by crystallization of amorphous silicon by solid phase crystallization (SPC) at $600{ }^{\circ} \mathrm{C}$.

In a recent publication ${ }^{9}$ it was already shown, that such a postdeposition thermal treatment can lead to improved mobility in aluminum-doped zinc oxide thin films if they are protected from oxidation by a silicon capping layer. After a $20 \mathrm{~h}$ long treatment the mobility was raised from 42 to $53 \mathrm{~cm}^{2} / \mathrm{Vs}$ while the carrier concentration remained at $3.5 \times 10^{20} \mathrm{~cm}^{-3}$.

The aim of this work was to study the influence of the annealing conditions on the mobility change and the effect of capping layer thickness on long-term thermal stability. Reasons for the observed increases in mobility and carrier concentration are discussed.

In Sec. II the experimental procedures for film deposition, thermal treatments and characterization are discussed. The results are organized into four parts. In the first part we discuss the influence of temperature treatments on uncapped 
films [Sec. III A], in Sec. III B the influence of the capping layer deposition process and its thickness is discussed while in Sec. III C the influence of annealing time and temperature is examined. In Sec. III D we investigate the influence of the capping layer on the Hall measurements and prove the reliability of the measurements with the capping layer in place.

\section{EXPERIMENTAL DETAILS}

The aluminum-doped zinc oxide ( $\mathrm{ZnO}: \mathrm{Al})$ layers used for this investigation were all prepared by nonreactive radio frequency $(\mathrm{RF})$ magnetron sputtering using a ceramic target with an $\mathrm{Al}_{2} \mathrm{O}_{3}$-concentration of $1 \mathrm{wt} \%{ }^{6}$ A substrate temperature of around $300{ }^{\circ} \mathrm{C}$ was used in all cases.

Two different glass substrate were used: for the annealing studies on uncapped $\mathrm{ZnO}$ :Al layers, films deposited onto Corning 1737 glass were used. In the experiments on capped ZnO:Al films Schott Borofloat 33 glass with an $80 \mathrm{~nm}$ thick SiN diffusion barrier deposited by plasma-enhanced CVD (PECVD), supplied by CSG Solar, were used. This type of substrate exhibits a coefficient of thermal expansion similar to the one of silicon and is thus suitable as substrate in the production of polycrystalline Si solar cells by a SPC process at $600{ }^{\circ} \mathrm{C}$.

The $\mathrm{ZnO}$ :Al samples on the CSG substrate were thoroughly cleaned and then coated with n-type amorphous silicon films by PECVD. Alternatively, silicon layers were deposited using e-beam evaporation. In this case no intentional doping of the silicon capping layer was carried out.

Annealing was carried out in a quartz tube furnace under nitrogen atmosphere in all cases. Details on temperature profiles can be found in the appropriate result sections.

Optical measurements were carried out using a Perkin Elmer Lambda 19 spectrophotometer equipped with an integrating sphere in the spectral range from 250 to $2500 \mathrm{~nm}$. In order to gain more information on the three-layer stack, reflection was measured from the film side and the glass side additionally to transmission. The spectra were analyzed by simultaneously fitting all three spectra, where a TaucLorentz oscillator ${ }^{10}$ was used for the dispersion of the amorphous silicon layer while the model used to describe the $\mathrm{ZnO}: \mathrm{Al}$ layer has already been presented elsewhere. ${ }^{11}$

From the fits to the optical spectra the film thicknesses of all involved layers were confirmed and the modeled plasma frequency $\Omega_{p}$ was used to calculate the carrier concentration in the $\mathrm{ZnO}: \mathrm{Al} \mathrm{film}$, using electron effective masses as described elsewhere. ${ }^{12}$ Hall measurements were carried out using a standard van der Pauw geometry at room temperature.

\section{RESULTS}

\section{A. Annealing of uncapped $\mathrm{ZnO}$ :Al films}

The thermal stability of Al-doped $\mathrm{ZnO}$ films is known to depend on the deposition conditions of the films. ${ }^{13,14}$ In order to find out the behavior for our films, we annealed uncapped $\mathrm{ZnO}: \mathrm{Al}$ layers in the same annealing environment as the capped layers discussed in the following sections. The experiments were carried out at 450 and $500{ }^{\circ} \mathrm{C}$. At these temperatures the degradation of electrical properties was slow enough so that we could observe the change in electron con-

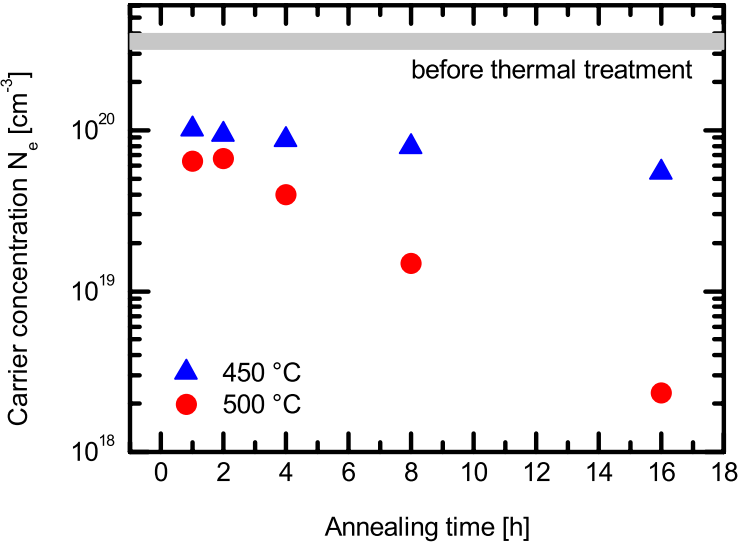

FIG. 1. (Color online) Carrier concentration of $\mathrm{ZnO}$ :Al films after thermal annealing in nitrogen ambient vs annealing time. Initial carrier concentration of all films was between 3 and $4 \times 10^{20} \mathrm{~cm}^{-3}$.

centration and mobility over time. In all cases the samples were directly placed into the preheated oven. The results for the carrier concentration as determined by Hall measurements are shown in Fig. 1.

As can be seen the carrier concentration of the films strongly decreased with increasing annealing time. After $16 \mathrm{~h}$ of annealing at $450{ }^{\circ} \mathrm{C}$, it was reduced by more than $80 \%$ as compared to the initial state, while degradation by two orders of magnitude was observed in the case of annealing at $500{ }^{\circ} \mathrm{C}$. The mobility was reduced along with the carrier concentration (see Fig. 2).

Other annealing experiments on doped $\mathrm{ZnO}$ have been carried out by various groups. Reports describing improved electrical transport often refer to sol-gel deposited films, ${ }^{15-17}$ but for films deposited by sputtering or pulsed laser deposition (PLD), improved electrical transport has only been reported for annealing at moderate temperatures of $350{ }^{\circ} \mathrm{C}$ in nitrogen ${ }^{18}$ and up to $500{ }^{\circ} \mathrm{C}$ in vacuum..$^{19,20}$

For temperatures of $400{ }^{\circ} \mathrm{C}$ and higher only annealing in hydrogen ${ }^{21,22}$ or forming gas ${ }^{23}$ leads to improved conductivity. In nitrogen, oxygen, ${ }^{23}$ and air $^{21,24}$ a decrease in conductivity is obtained. This effect was found to be reversible. ${ }^{25,26}$

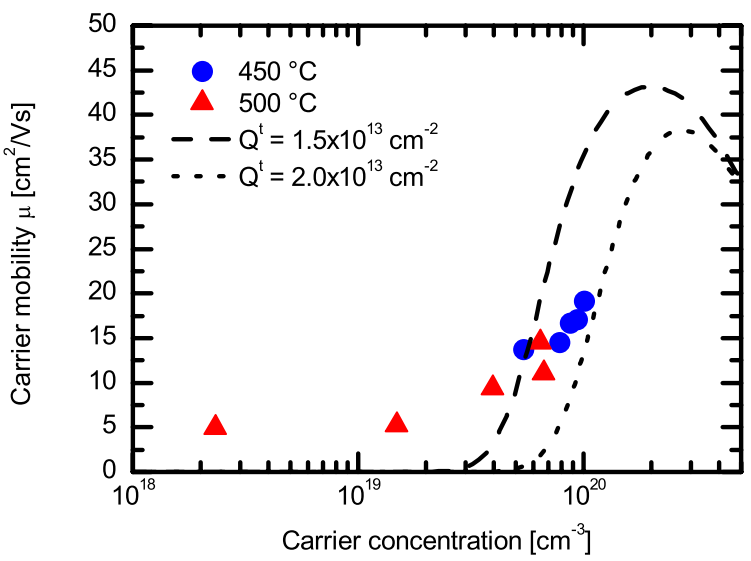

FIG. 2. (Color online) Mobility of $\mathrm{ZnO}: \mathrm{Al}$ films after thermal annealing in nitrogen ambient versus carrier concentration. The dotted lines are mobilities calculated using Seto's model (Ref. 32) to describe the contribution for grain boundary scattering. For the two curves different values for defect density $Q^{t}$ at the grain boundaries have been assumed. 
The lowest decrease in conductivity was generally reported for annealing in vacuum. Here resistivity increase was mainly observed for temperatures above $600{ }^{\circ} \mathrm{C}$ or for higher residual gas pressures. ${ }^{24}$ The effect has also been used to decrease carrier concentration in a controlled way. ${ }^{27}$ In nitrogen a high thermal stability, along with a remarkable improvement of electrical transport, was only reported for rapid thermal annealing of epitaxial films. ${ }^{28}$

From the above cited results it becomes clear, that oxygen is a main driver for resistivity increase. Unless hydrogen is added to the ambient, even low oxygen concentrations like in nitrogen gas or in the residual gas in vacuum annealing lead to decreased conductivity. It has been suggested that oxygen can decrease the conductivity by chemisorption at grain boundaries, thus increasing the contribution of grain boundary scattering. ${ }^{25}$ In this case mainly a decreased carrier mobility is expected.

A decrease in carrier concentrations could be caused by the formation of oxygen interstitials, which has been experimentally observed. ${ }^{26}$ Theoretical work has suggested a formation of a large amount of zinc vacancies even at low oxygen partial pressures instead. ${ }^{29}$

In order to find out more on the degradation of our films, the measured mobilities have been plotted as a function of the carrier concentration in Fig. 2. The annealing procedure moved the films toward lower carrier concentration and lower carrier mobility. As already described by Minami et $a l .^{24}$ this is not an effect caused by deterioration of crystal quality or defect formation, but a natural cause of grain boundary scattering in polycrystalline films, which leads to lower mobilities for lower carrier concentrations in the range of carrier concentrations obtained in this series.

In order to visualize the effect of grain boundary scattering, mobility values have also been calculated and plotted into Fig. 2. The curves were calculated using the mobility limit proposed by Ellmer et al. ${ }^{30}$ who used the expression derived by Masetti ${ }^{31}$ for mobility in monocrystalline silicon and adapted the parameters to experimental results for zinc oxide, and the grain boundary scattering theory by Seto. ${ }^{32}$ For the latter model, a grain size of $50 \mathrm{~nm}$ and defect densities $Q^{t}$ of $1.5 \times 10^{13}$ and $2.0 \times 10^{13} \mathrm{~cm}^{-2}$ have been used. The total mobility reaches a maximum in the range of some $10^{20} \mathrm{~cm}^{-3}$ charge carriers. For higher carrier concentrations total mobility is limited by ionized impurity scattering, while grain boundary scattering is the limiting factor for lower carrier concentrations.

While no perfect agreement between theory and experiment is observed, the general trend of decreasing mobility with decreasing carrier concentration in the examined range is well described using defect densities close to the values proposed by Ellmer et al. ${ }^{30}$ Thus we cannot conclude any deterioration of transport properties, other than barrier height at the grain boundaries, due to the annealing. It should be noted that one cannot expect a better agreement between theory and experiment due to the simplicity of the Seto model and the fact, that the curves are calculated assuming a constant defect density $Q^{t}$. The general trend of the data in Fig. 2 even suggests a decrease in $Q^{t}$ with annealing, as also found by Ellmer et al. ${ }^{30}$
TABLE I. Summary of annealing experiments carried out with various silicon capping layers with different annealing conditions. The treatment time $t$ includes both the heating time from 250 to $600{ }^{\circ} \mathrm{C}$ and the plateau time $\tau_{p}$, the time for which the sample was kept at maximum temperature.

\begin{tabular}{cccc}
\hline \hline \multicolumn{4}{c}{ Thermal treatment } \\
\hline $\begin{array}{c}\text { Ramp speed } R \\
(\mathrm{~K} / \mathrm{min})\end{array}$ & $\begin{array}{c}\text { Plateau time } \\
(\mathrm{h})\end{array}$ & $\begin{array}{c}\text { Plateau temperature } T_{p} \\
\left({ }^{\circ} \mathrm{C}\right)\end{array}$ & $\begin{array}{c}\text { Treatment time } t \\
(\mathrm{~h})\end{array}$ \\
\hline 5 & 0 & 600 & 2.3 \\
2 & 0 & 600 & 5.8 \\
1 & 0 & 600 & 11.7 \\
0.5 & 0 & 600 & 23.3 \\
1.6 & 24 & 600 & 31.3 \\
1.6 & 72 & 600 & 79.3 \\
\hline \hline
\end{tabular}

\section{B. Annealing of capped ZnO:Al layers using different capping layers}

The degradation of $\mathrm{ZnO}$ :Al films during annealing, as observed and described in the previous section, can be successfully prevented using a suitable barrier layer on top of the $\mathrm{ZnO}$ film. Silicon was found to be a suitable barrier layer, ${ }^{9}$ as it seems to prevent oxygen migration into the $\mathrm{ZnO}$ film. In these first investigations a silicon film with a thickness of around $290 \mathrm{~nm}$ has been used as a capping layer. We aimed at decreasing the thickness of the barrier film in order to find the minimum film thickness required to guarantee thermal stability for annealing at $600{ }^{\circ} \mathrm{C}$. Capping layers of n-type amorphous silicon with thicknesses of 15, 50 and $150 \mathrm{~nm}$ deposited by PECVD were used as well as undoped layers with a thickness of $40 \mathrm{~nm}$ deposited by e-beam evaporation.

An annealing temperature of $600{ }^{\circ} \mathrm{C}$ was chosen, as this is a common temperature used for crystallization of amorphous silicon and thus the $\mathrm{ZnO}: \mathrm{Al} / \mathrm{Si}$ stacks have to withstand this temperature. At this temperature it was impossible to directly place the samples into the preheated oven, as severe cracking was observed for some samples. Instead the samples were placed into the oven at $250^{\circ}$ and preheated for $1 \mathrm{~h}$, before the temperature was raised up to $600{ }^{\circ} \mathrm{C}$ using different heating ramps. After reaching maximum temperature the samples were cooled down again at the same speed. Further samples were held at $600{ }^{\circ} \mathrm{C}$ for up to $72 \mathrm{~h}$ before cooling down again. The experiments are summarized in Table I.

A first inspection of the samples after annealing showed, that the silicon thickness has a strong influence on the mechanical stability of the layer stack upon annealing. Only the samples with a thin Si capping layer of $15 \mathrm{~nm}$ showed cracking, which for some samples appeared a few days after the annealing process. The cracking did not result in strong light scattering, so optical spectra could be recorded and evaluated, yielding local information on electrical transport properties. As cracking did also not affect the complete sample surface, Hall measurements could be carried out as well.

The carrier concentrations determined by Hall measurements are shown in Fig. 3. For the thickest a-Si:H layers of $150 \mathrm{~nm}$, Hall measurements were difficult to carry out and 


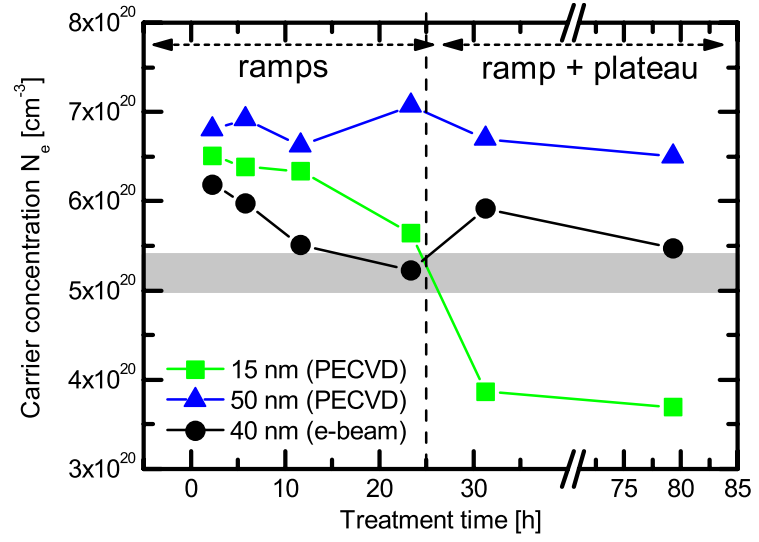

FIG. 3. (Color online) Carrier concentration as determined by Hall measurements of capped ZnO:Al layers treated as described in Table I. Before annealing the films exhibited carrier concentrations determined by Hall measurements of $(5.2 \pm 0.2) \times 10^{20} \mathrm{~cm}^{-3}$, regardless whether measured before or after silicon capping. The range is marked by the gray bar.

were thus omitted in the figure. For these samples the evaluation of electrical transport properties was done only by analysis of optical data.

For short treatment times we found significantly increased carrier concentrations as compared to the unannealed films. The lowest increase is obtained for the capping layer deposited by e-beam evaporation, while for the capping layers deposited by PECVD the increase in carrier concentration is larger for higher capping layer thicknesses. This is also confirmed by the evaluation of optical spectra for the $150 \mathrm{~nm}$ thick capping layers, for which the $\mathrm{ZnO}$ : $\mathrm{Al}$ layers underneath show the highest carrier concentrations after annealing (not shown in Fig. 3).

For longer treatment times the samples with the thinnest silicon cap of $15 \mathrm{~nm}$ show reduced carrier concentration which even falls below the initial value if held at $600{ }^{\circ} \mathrm{C}$ for several hours. Apparently the thickness of the capping layer is too low to offer long-term thermal stability.

For the other capping layer thicknesses there is only a very slight trend for lower carrier concentrations for longer treatment times. A final conclusion is hard to draw, as variations most probably caused by inhomogeneity of the untreated samples and by variations in the effect leading to the increased carrier concentration, which will be discussed in Sec. IV, also occur. For our purposes the samples can be regarded as stable at the tested annealing conditions.

The Hall measurements of the annealed samples also showed the beneficial effect of thermal treatments on the mobility of the $\mathrm{ZnO}$ films. The mobility values for the samples are shown in Fig. 4. For all samples the mobility was raised during annealing and already after ramping the temperature to $600{ }^{\circ} \mathrm{C}$ values around $55 \mathrm{~cm}^{2} / \mathrm{Vs}$ were achieved. For the samples held at $600{ }^{\circ} \mathrm{C}$ the highest values of mobility measured were around $65 \mathrm{~cm}^{2} / \mathrm{Vs}$, which were achieved for Si capping layers with a thickness of $40 \mathrm{~nm}$ or more. Thus longer annealing at the peak temperature has a significant effect.

\section{Influence of annealing temperature}

Due to the results obtained in the previous section, further experiments were carried out with a capping layer thick-

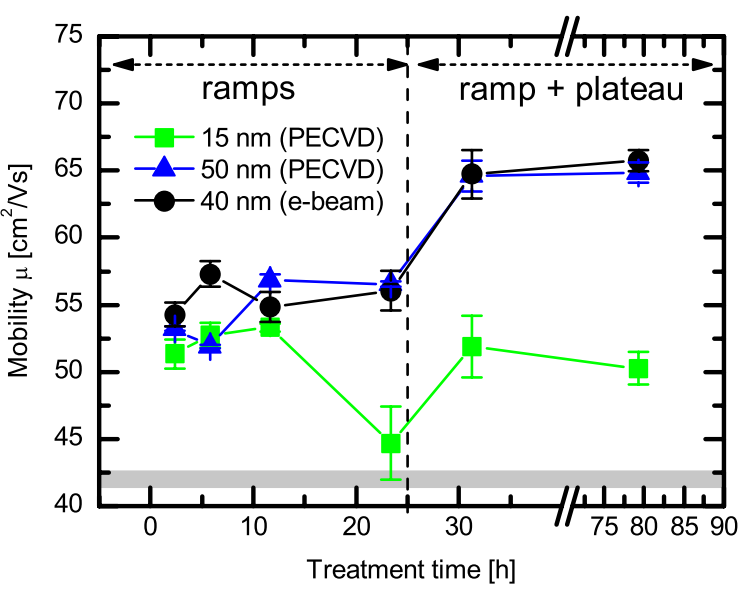

FIG. 4. (Color online) Mobility determined Hall measurements of capped $\mathrm{ZnO}: \mathrm{Al}$ layers treated as described in Table I. Before annealing the films exhibited mobilities of $42 \pm 0.5 \mathrm{~cm}^{2} / \mathrm{Vs}$, regardless whether measured before or after silicon capping.

ness of $50 \mathrm{~nm}$ deposited by PECVD and a ramping speed $R$ of $1.6 \mathrm{~K} / \mathrm{min}$. Different plateau temperatures ranging from 500 to $650{ }^{\circ} \mathrm{C}$ and different plateau annealing times between 0 , thus only the temperature ramp, and $72 \mathrm{~h}$ were investigated. Higher temperatures than $650{ }^{\circ} \mathrm{C}$ could not be tested as the glass substrates used do not withstand such temperatures for a long time. The resulting carrier concentrations are shown in Fig. 5.

As for the previous experiments, the carrier concentration is raised as compared to the level of untreated films. Regardless of plateau temperature, all values are in a similar range around $7 \times 10^{20} \mathrm{~cm}^{-3}$. This value was maintained even for longer annealing up to $24 \mathrm{~h}$ and only the longest annealing time of $72 \mathrm{~h}$ led to a slight reduction in carrier concentration.

The corresponding mobility values are shown in Fig. 6. In all cases the mobility is raised by a factor of 1.5 above the untreated value even for very short treatment times. For a given plateau temperature the mobility already shows a strong increase during the ramp and is further raised in the first $6 \mathrm{~h}$ at plateau temperature, with only smaller changes for longer annealing times.

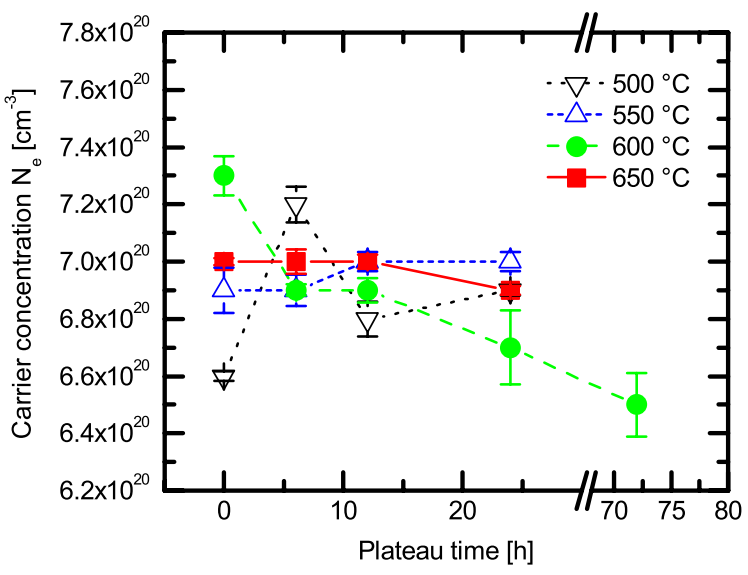

FIG. 5. (Color online) Carrier concentration of $\mathrm{ZnO}$ :Al films capped with silicon after thermal treatment at various temperatures for different times. Before annealing the carrier concentration of the films was around $(5.5 \pm 0.2) \times 10^{20} \mathrm{~cm}^{-3}$. 


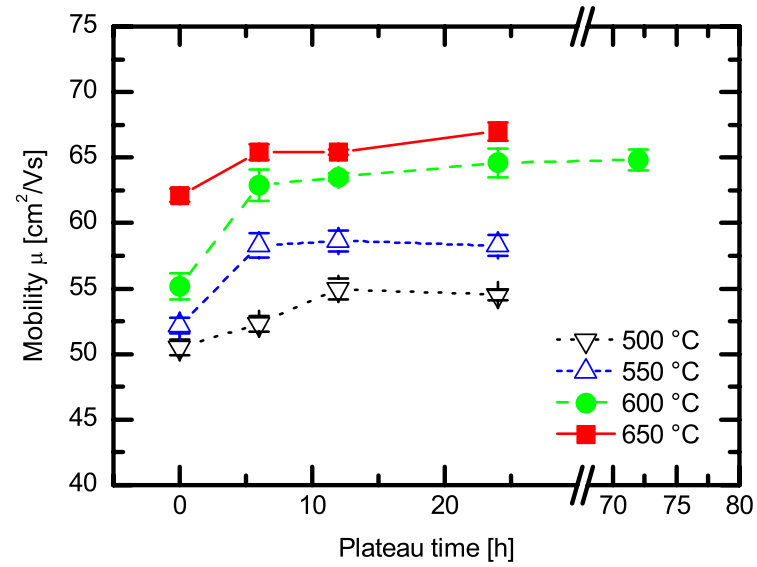

FIG. 6. (Color online) Mobility of ZnO:Al films capped with silicon after thermal treatment at various temperatures for different times. Before annealing the films exhibited mobilities of $42 \pm 0.5 \mathrm{~cm}^{2} / \mathrm{Vs}$.

A strong dependence on the plateau temperature is also found, with the maximum mobility achieved raising with plateau temperature. For the maximum temperature of $650{ }^{\circ} \mathrm{C}$, the gain as compared to $600{ }^{\circ} \mathrm{C}$ is mainly seen in the speed at which the maximum mobility is reached, longer annealing only leads to a small increase in mobility. Nevertheless the highest mobility observed at $67 \mathrm{~cm}^{2} / \mathrm{Vs}$ was reached for annealing at $650{ }^{\circ} \mathrm{C}$.

The combination of high mobilities with rather high carrier concentrations means that the films exhibit very low resistivities even below $140 \mu \Omega \mathrm{cm}$. For clarity the values are also displayed in Fig. 7. This means that postdeposition treatment using silicon capping of the films has increased the conductivity of the already high quality films by a further factor of 2 .

Resistivities below $200 \mu \Omega \mathrm{cm}$ have already been reported by other researchers. High quality films have been repeatedly achieved by PLD, ${ }^{33-36}$ with Agura and co-workers ${ }^{33}$ having published a minimum resistivity of $85 \mu \Omega \mathrm{cm}$. These high values were mostly achieved by a very high carrier concentration, exceeding $10^{21} \mathrm{~cm}^{-3}$, while maximum mobilities were around $50 \mathrm{~cm}^{2} /$ Vs. For sputtered films similar properties were achieved by Igasaki on sapphire substrates. ${ }^{37,38}$ Nevertheless the emphasis in TCO research

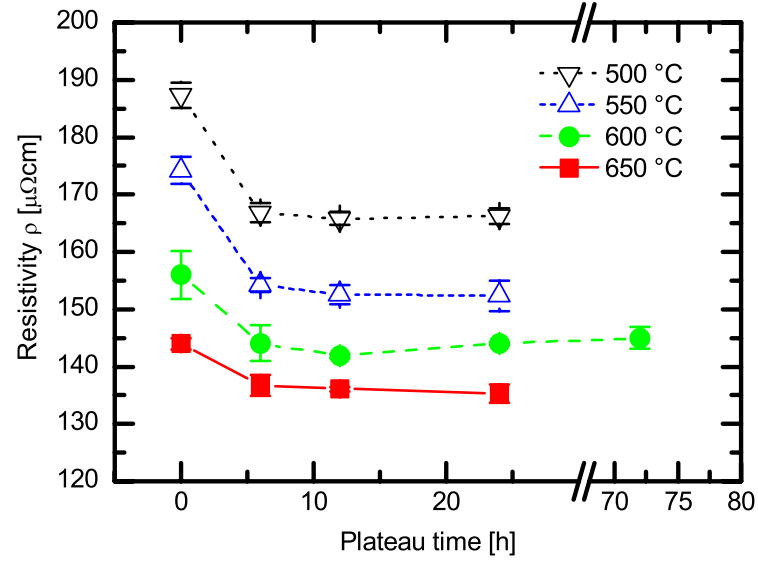

FIG. 7. (Color online) Resistivity of the $\mathrm{ZnO}: \mathrm{Al}$ films already discussed in Figs. 5 and 6 after thermal treatment at various temperatures for different times. Before annealing the films had resistivities around $270 \mu \Omega \mathrm{cm}$. After annealing the films display very low resistivities for sputtered films.

for photovoltaics is on high mobilities. As deposited films, usually prepared by various magnetron sputtering processes, on glass usually have mobilities up to around $40 \mathrm{~cm}^{2} / \mathrm{Vs}$ at carrier concentrations between 2 and $8 \times 10^{20} \mathrm{~cm}^{-3}$ [see for instance (Ref. 39)]. Nevertheless significantly higher mobilities have been reported.

A non exhaustive summary of high mobility $\mathrm{ZnO}$ thin films with carrier concentrations above $1 \times 10^{20} \mathrm{~cm}^{-3}$ is given in Table II. There is a clear trend for lower mobilities with increasing carrier concentrations that can be attributed to the effect of ionized impurity scattering. ${ }^{49-51}$ This effect, as well as the influence of grain boundary scattering has been discussed in comprehensive reviews. ${ }^{30,39,52}$

As grain boundary scattering plays an important role in films with doping levels in the low $10^{20} \mathrm{~cm}^{-3}$ regime we can conclude, that high mobilities can only be reached if the defect density at the grain boundaries can be kept low. In this respect some of the results given in Table II are remarkable in that the deposition processes and postdeposition treatments used seem to limit defect densities at the grain boundaries to a minimum. Note that some of the results have been achieved by heteroepitaxial growth on sapphire ${ }^{28,40}$ or placing substrates perpendicular to the target in magnetron

TABLE II. Examples of publications that have shown high mobilities in zinc oxide films with carrier concentrations above $1 \times 10^{20} \mathrm{~cm}^{2} /$ Vs. Films have been deposited by radio frequency magnetron sputtering (RFMS), direct current magnetron sputtering (DCMS) and PLD.

\begin{tabular}{lcccccc}
\hline \hline Material & Substrate & $\begin{array}{c}\text { Deposition } \\
\text { method }\end{array}$ & $\begin{array}{c}N_{e} \\
\left(10^{20} \mathrm{~cm}^{-3}\right)\end{array}$ & $\begin{array}{c}\mu \\
\left(\mathrm{cm}^{2} / \mathrm{Vs}\right)\end{array}$ & $\begin{array}{c}\rho \\
(\mu \Omega \mathrm{cm})\end{array}$ & Reference \\
\hline ZnO:Al, ZnO:Ga & Sapphire & PLD & $\sim 1$ & $\sim 70$ & $\sim 900$ & 40 \\
$\mathrm{ZnO}$ & Glass & RFMS & 1.1 & 120 & 450 & 41 and 42 \\
$\mathrm{ZnO}:(\mathrm{Al}, \mathrm{H})$ & Glass & RFMS & 1.7 & $\sim 50$ & $\sim 700$ & 43 \\
$\mathrm{ZnO}: \mathrm{Al}$ & Sapphire & RFMS+RTA & 1.8 & 66 & 520 & 28 \\
$\mathrm{ZnO}: \mathrm{B}$ & Glass & DCMS & 2.0 & 60 & 400 & 44 \\
$\mathrm{ZnO}: \mathrm{Al}$ & Glass & DCMS & 2.6 & 57 & 420 & 45 \\
$\mathrm{ZnO}: \mathrm{Al}$ & Glass & RFMS & 4.3 & 53 & 273 & 46 \\
$\mathrm{ZnO}: \mathrm{Al}$ & Glass & RFMS & $\sim 5.5$ & 49 & $\sim 230$ & 47 \\
$\mathrm{ZnO}: \mathrm{Al}$ & Silica & RPMS & 6.0 & 46 & 226 & 48 \\
$\mathrm{ZnO}: \mathrm{Al}$ & Glass & RFMS+Anneal & 6.9 & 67 & 135 & This work \\
\hline \hline
\end{tabular}


sputtering. ${ }^{41,42}$ Adding the postdeposition treatment at high temperatures while preventing degradation of the film via a capping layer has been the key in this work to achieve high carrier mobilities above $65 \mathrm{~cm}^{2} / \mathrm{Vs}$ even at carrier concentrations above $5 \times 10^{20} \mathrm{~cm}^{-3}$.

\section{Verification of Hall measurements}

All Hall measurements carried out in the presented work were done after the annealing process, with the capping layer still present on the $\mathrm{ZnO}: \mathrm{Al}$ film. This has led to the question, whether the result of the Hall measurement is significantly influenced by the capping layer. If the two layers can be regarded as parallel conductors, no influence is expected. This is mainly due to the high resistivity of the capping layer $\left(\sim 5 \times 10^{4} \Omega \mathrm{cm}\right.$ for the PECVD deposited Si films) and its low thickness. A higher conductivity of the capping layer is only obtained if the cap crystallizes during the annealing procedure. This was only the case for treatments over $6 \mathrm{~h}$ at $600{ }^{\circ} \mathrm{C}$ or higher as confirmed by Raman spectroscopy. Even in this case the mobility of a Si layer deposited on glass was determined to be $27 \mathrm{~cm}^{2} / \mathrm{Vs}$, which will not influence the overall resistance of the two layer stack significantly. Nevertheless a redistribution of carriers could take place between the layers and high mobility paths could be formed at the interface between the layers.

The most simple approach to check this is to remove the capping layer and repeat the measurement. This was achieved by plasma etching in a PECVD reactor for silicon deposition on $10 \times 10 \mathrm{~cm}^{2}$ substrates. The samples were glued by silver paste to a glass substrate and etched in an RF discharge with $\mathrm{NF}_{3}$ gas at room temperature. Due to the high selectivity of this process no $\mathrm{ZnO}$ etching was detected even though a long etch time was chosen in order to be sure, that all silicon was removed.

The feasibility of the procedure was only questioned by the high sensitivity of resistivity of the surface regions of $\mathrm{ZnO}$ films to exposure to plasmas or different atmospheres at elevated temperatures, which is often used in sensor devices. In order to investigate this effect, Hall measurements were carried out on some samples directly before and after the plasma treatment, thus with the Si cap in place and after its removal. For these samples the mobility values determined before and after etching were equal within the experimental error, considered to be around 5\%. The change in sheet resistance was negligible.

For the rest of the samples discussed in Sec. III B the decapping procedure was carried out on a different part of the sample than the Hall measurements shown before. Here both higher and lower mobilities were determined after the decapping, with deviation around $10 \%$ in both directions. Thus no systematic influence of the capping layer on the Hall measurement was found.

In summary we have shown the reliability of our Hall measurements for Si capping layers for cap thicknesses up to at least $50 \mathrm{~nm}$. The Hall data shown can thus be regarded as correct within its experimental error.

\section{DISCUSSION}

The results discussed in Secs. III B and III C show clearly, that postdeposition thermal treatment of capped layers is an appealing way to increase the conductivity of already high quality $\mathrm{ZnO}$ :Al layers. The capping layer efficiently prevents degradation of the films as it was observed for uncapped layers. Only for very thin capping layers $(15 \mathrm{~nm})$ a slight degradation was observed for longer annealing times.

As was already pointed out earlier, oxygen in the annealing atmosphere is a major cause for the reduction in carrier concentration during high temperature annealing of uncapped films. While for the thin capping layers oxygen migration through microcracks cannot be ruled out, also bulk diffusion through an intact capping layer could occur. This would explain the fact, that thicker capping layers offer a higher protection from the influence of oxygen.

For the capped layers, an increase in carrier concentration was observed after short thermal treatments. Several effects could cause this effect:

- activation of intrinsic or extrinsic donors;

- passivation of acceptors states;

- creation of intrinsic donors; and

- diffusion of extrinsic donors into the $\mathrm{ZnO}: \mathrm{Al}$.

The first three possibilities, like an activation of excess (inactive) $\mathrm{Al}$ dopants, can be ruled out, as the large differences found in between different samples (see Fig. 3) cannot be explained. Also a similar treatment which we reported earlier has shown to lead to no change in carrier concentration. ${ }^{9}$ The only difference from the experiments in this work is the lack of a SiN layer between the $\mathrm{ZnO}: \mathrm{Al}$ and the glass substrate.

Thus the special setup of the samples used in this study has to be taken into account. The SiN barrier between the glass substrate and the $\mathrm{ZnO}: \mathrm{Al}$ film was deposited by PECVD and thus contains a significant amount of hydrogen. Also the capping layers deposited by PECVD contain large amounts of hydrogen in the as-deposited state. The hydrogen will readily diffuse at the treatment temperatures and is a well known source of excess carriers in $\mathrm{ZnO}: \mathrm{Al}$ films. ${ }^{53-55}$

In order to clarify this effect, experiments with sputtered $\mathrm{SiN}$ layers were carried out and showed, that the increase in carrier concentration is significantly reduced with these hydrogen-free barrier layers. Thus the hydrogen from the $\mathrm{SiN}$ layer can be regarded as responsible for a part of the increase in $N_{e}$.

Further carriers can originate from the capping layer. Considering that the hydrogen concentration in the PECVD Si layers is in the range of $5 \times 10^{21} \mathrm{~cm}^{-3}$, even a very thin layer of $15 \mathrm{~nm}$ contains enough hydrogen to explain an increase in $N_{e}$ in the order of some $10^{19} \mathrm{~cm}^{-3}$.

The assumption, that also the hydrogen in the capping layer is a source for additional carriers on the $\mathrm{ZnO}$ film after the annealing procedure is also supported by the fact, that the carrier concentration for short annealing times seems to scale with capping layer thickness, with the capping layer deposited by e-beam evaporation showing the lowest increase in 


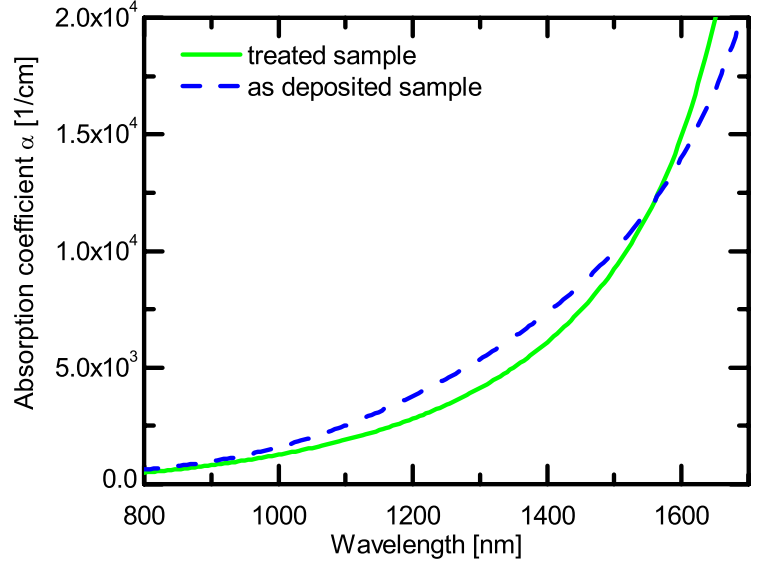

FIG. 8. (Color online) Absorption coefficient derived from fits to optical spectra of one capped but untreated sample and a heat treated sample. Both samples have comparable carrier concentrations, while the treated sample has a significantly higher mobility. Details on the samples are in Table III.

carrier concentration due to the lack of hydrogen. Thus we conclude that the increase in carrier concentration is caused by the diffusion of hydrogen from both the capping layer and the $\mathrm{SiN}$ barrier into the $\mathrm{ZnO}: \mathrm{Al}$ layer.

Finally a strong increase in mobility is seen after the annealing procedure. As ionized impurity scattering is only influenced by the amount of carriers in the films, the annealing must have an effect on one or several of the other scattering mechanisms. It is reasonable to assume, that the main effect is a decrease of defects at the grain boundaries, but also the decrease of neutral impurity scattering or scattering at crystallographic defects such as dislocations could be a possible reason. Unfortunately most of the defects responsible for the scattering cannot be easily accessed spectroscopically, so a final conclusion is hard to derive.

It is worthwhile to also take a look at the optical properties of the films. One expected advantage of high mobilities is a sharper raise of the absorption coefficient close to the plasma frequency, meaning that the absorption in the transparent spectral range will remain low even close to the plasma edge.

From the data gathered this is hard to derive, as the silicon capping layer, depending on thickness, strongly changes the transmission and reflection spectra. Thus a thorough fit of the optical data was preformed and the dielectric function of the $\mathrm{ZnO}: \mathrm{Al}$ film was derived from the fit (Fig. 8). The procedure was done for a capped but untreated sample and for an annealed sample with a comparable carrier concentration. Thus the differences of the optical spectra can be solely attributed to the different mobilities.

From the absorption coefficient we can clearly see the beneficial effect of the increased mobility. In the visible range at low wavelength the absorption in the treated film with the higher mobility is smaller than in the untreated sample. Even at low absorption coefficients this can have a significant effect in solar cells, when light trapping schemes are applied, that will increase the red-response of low bandgap solar cells like $\mu \mathrm{c}$-Si solar cells. ${ }^{5}$ The absorption of the high mobility film for higher wavelengths is not an issue for the solar cell as long as the plasma frequency is below the bandgap of the absorber.

\section{SUMMARY}

In summary we have presented a way to strongly increase the conductivity of $\mathrm{ZnO}: \mathrm{Al}$ films by high temperature treatments. The key to prevent degradation of the films during heat treatment is to use a capping layer. We found amorphous silicon to be a suitable material that provides protection from oxygen diffusion into the $\mathrm{ZnO}: \mathrm{Al}$ even at low thicknesses.

The treated films repeatedly exhibit remarkably high mobilities well above $60 \mathrm{~cm}^{2} / \mathrm{Vs}$, a value that is hard to achieve with any deposition method for films with carrier concentrations in the $10^{20} \mathrm{~cm}^{-3}$ range. Thus $\mathrm{ZnO}: \mathrm{Al}$ can display very low resistivities below $150 \mu \Omega \mathrm{cm}$. The annealing procedure presented is also fully compatible with large area technology. Thus, such high mobility $\mathrm{ZnO}$ :Al films can be optimum front contacts for solar cells with low bandgap absorbers, as the plasma frequency can be kept low by low doping and high conductivities can be reached nevertheless.

\section{ACKNOWLEDGMENTS}

The authors would like to thank E. Conrad, K. Jacob, A. Scheu, S. Common, J. Owen, and M. Muske for extensive technical assistance. We also like to thank CSG Solar for providing the Borofloat substrates coated with $\mathrm{SiN}$ and our partners in the joint project LiMa. Funding of this project by the Federal Ministry for the Environment, Nature Conservation and Nuclear Safety BMU under Contract No. 0327693H is gratefully acknowledged.

${ }^{1}$ E. Fortunato, D. Ginley, H. Hosono, and D. C. Paine, MRS Bull. 32, 242 (2007).

${ }^{2}$ T. Minami and T. Miyata, Thin Solid Films 517, 1474 (2008).

${ }^{3}$ C. G. Granqvist, Sol. Energy Mater. Sol. Cells 91, 1529 (2007).

${ }^{4}$ S. Faÿ and A. Shah, in Transparent Conducting Zinc Oxide, Springer Series in Materials Science 104, edited by K. Ellmer, A. Klein, and B. Rech, (Springer, Berlin Heidelberg, 2008).

${ }^{5}$ J. Müller, B. Rech, J. Springer, and M. Vanecek, Sol. Energy 77, 917 (2004).

${ }^{6}$ C. Agashe, O. Kluth, J. Hüpkes, U. Zastrow, B. Rech, and M. Wuttig, J. Appl. Phys. 95, 1911 (2004).

${ }^{7}$ M. J. Keevers, T. L. Young, U. Schubert, and M. A. Green, Proceedings of the 22nd European Photovoltaic Solar Energy Conference, Milan, Italy, 2007 (unpublished), pp. 1783-1790.

${ }^{8}$ C. Becker, E. Conrad, P. Dogan, F. Fenske, B. Gorka, T. Hänel, K. Y. Lee, B. Rau, F. Ruske, T. Weber, M. Berginski, J. Hüpkes, S. Gall, and B. Rech, Sol. Energy Mater. Sol. Cells 93, 855 (2009).

${ }^{9}$ K. Y. Lee, C. Becker, M. Muske, F. Ruske, S. Gall, B. Rech, M. Berginski, and J. Hüpkes, Appl. Phys. Lett. 91, 241911 (2007).

${ }^{10}$ G. E. Jellison, Jr. and F. A. Modine, Appl. Phys. Lett. 69, 371 (1996).

${ }^{11}$ A. Pflug, V. Sittinger, F. Ruske, B. Szyszka, and G. Dittmar, Thin Solid Films 455-456, 201 (2004).

${ }^{12}$ F. Ruske, A. Pflug, V. Sittinger, B. Szyszka, D. Greiner, and B. Rech, Thin Solid Films, 518,1289 (2009).

${ }^{13}$ F.-J. Haug, Zs. Geller, H. Zogg, A. N. Tiwari, and C. Vignali, J. Vac. Sci. Technol. A 19, 171 (2001).

${ }^{14}$ T. Minami, K. Oohashi, S. Takata, T. Mouri, and N. Ogawa, Thin Solid Films 193/194, 721 (1990).

${ }^{15}$ R. Bel Hadj Tahar and N. Bel Hadj Tahar, J. Appl. Phys. 92, 4498 (2002).

${ }^{16}$ S.-Y. Kuo, W.-C. Chen, F.-I. Lai, C.-P. Cheng, H.-C. Kuo, S.-C. Wang, and W.-F. Hsieh, J. Cryst. Growth 287, 78 (2006).

${ }^{17}$ P. Nunes, E. Fortunato, and R. Martins, Thin Solid Films 383, 277 (2001).

${ }^{18}$ C. Lennon, R. Kodama, Y. Chang, S. Sivananthan, and M. Deshpande, J. Vac. Sci. Technol. B 27, 1641 (2009).

${ }^{19}$ X. Yu, J. Ma, Y. Wang, X. Zhang, and H. Ma, Thin Solid Films 483, 296 (2005).

${ }^{20}$ Y. Igasaki, M. Ishikawa, and G. Shimaoka, Appl. Surf. Sci. 33/34, 926 
(1988).

${ }^{21}$ S. Ghosh, A. Sarkar, S. Bhattacharya, S. Chaudhuri, and A. K. Pal, J. Cryst. Growth 108, 534 (1991).

${ }^{22}$ J. F. Chang, W. C. Lin, and M. H. Hon, Appl. Surf. Sci. 183, 18 (2001).

${ }^{23}$ B. Du Ahn, S. H. Oh, C. H. Lee, G. H. Kim, H. J. Kim, and S. Y. Lee, J Cryst. Growth 309, 128 (2007).

${ }^{24}$ T. Minami, T. Miyata, and T. Yamamoto, J. Vac. Sci. Technol. A 17, 1822 (1999).

${ }^{25}$ S. Takata, T. Minami, and H. Nanto, Thin Solid Films 135, 183 (1986).

${ }^{26}$ J. H. Noh, H. S. Jung, J.-K. Lee, J. Y. Kim, C. M. Cho, J. An, and K. S. Hong, J. Appl. Phys. 104, 073706 (2008).

${ }^{27}$ M. Berginski, B. Rech, J. Hüpkes, G. Schöpe, M. N. van den Donker, W Reetz, T. Kilper, and M. Wuttig, Proceedings of the 21st European Photovoltaic Solar Energy Conference, Dresden, 4-8 September 2006 (unpublished), p. 1539.

${ }^{28}$ K.-K. Kim, S. Niki, J.-Y. Oh, J.-O. Song, T.-Y. Seong, S.-J. Park, S. Fujita, and S.-W. Kim, J. Appl. Phys. 97, 066103 (2005).

${ }^{29}$ S. Lany and A. Zunger, Phys. Rev. Lett. 98, 045501 (2007).

${ }^{30}$ K. Ellmer and R. Mientus, Thin Solid Films 516, 4620 (2008).

${ }^{31}$ G. Masetti, M. Severi, and S. Solmi, IEEE Trans. Electron Devices 30, 764 (1983).

${ }^{32}$ J. Seto, J. Appl. Phys. 46, 5247 (1975).

${ }^{33}$ H. Agura, A. Suzuki, T. Matsushita, T. Aoki, and M. Okuda, Thin Solid Films 445, 263 (2003).

${ }^{34}$ M. Hiramatsu, K. Imaeda, N. Horio, and M. Nawata, J. Vac. Sci. Technol. A 16, 669 (1998).

${ }^{35}$ A. Suzuki, T. Matsushita, N. Wada, Y. Sakamoto, and M. Okuda, Jpn. J. Appl. Phys., Part 2 35, L56 (1996).

${ }^{36}$ H. Tanaka, K. Ihara, T. Miyata, H. Sato, and T. Minami, J. Vac. Sci. Technol. A 22, 1757 (2004).

${ }^{37}$ Y. Igasaki and H. Saito, J. Appl. Phys. 70, 3613 (1991)

${ }^{38}$ Y. Igasaki and H. Saito, J. Appl. Phys. 69, 2190 (1991)
${ }^{39}$ K. Ellmer, J. Phys. D 34, 3097 (2001).

${ }^{40}$ M. Lorenz, E. M. Kaidashev, H. von Wenckstern, V. Riede, C. Bundesmann, D. Spemann, G. Benndorf, H. Hochmuth, A. Rahm, H. C. Semmelhack, and M. Grundmann, Solid-State Electron. 47, 2205 (2003).

${ }^{41}$ T. Minami, H. Nanto, and S. Takata, Appl. Phys. Lett. 41, 958 (1982).

${ }^{42}$ H. Nanto, T. Minami, S. Shooji, and S. Takata, J. Appl. Phys. 55, 1029 (1984).

${ }^{43}$ J. N. Duenow, T. A. Gessert, D. M. Wood, D. L. Young, and T. J. Coutts, J. Non-Cryst. Solids 354, 2787 (2008).

${ }^{44}$ T. Nakada, Y. Ohkubo, N. Murakami, and A. Kunioka, Jpn. J. Appl. Phys., Part 1 34, 3623 (1995).

${ }^{45}$ B. Szyszka, S. Jäger, J. Szczyrbowski, and G. Bräuer, Surf. Coat. Technol. 98, 1304 (1998).

${ }^{46}$ R. Schäffler and H. W. Schock, Proceedings of the 23rd IEEE Photovoltaic Specialists Conference, Louisville, Kentucky, 10-14 May 1993 (unpublished), p. 1026.

${ }^{47}$ M. Berginski, J. Hüpkes, M. Schulte, G. Schöpe, H. Stiebig, B. Rech, and M. Wuttig, J. Appl. Phys. 101, 074903 (2007).

${ }^{48}$ S. Cornelius, M. Vinnichenko, N. Shevchenko, A. Rogozin, A. Kolitsch, and W. Moller, Appl. Phys. Lett. 94, 042103 (2009).

${ }^{49}$ J. R. Bellingham, W. A. Phillips, and C. J. Adkins, J. Phys.: Condens. Matter 2, 6207 (1990).

${ }^{50}$ J. R. Bellingham, W. A. Phillips, and C. J. Adkins, J. Mater. Sci. Lett. 11, 263 (1992).

${ }^{51}$ T. Pisarkiewicz, K. Zakrzewska, and E. Leja, Thin Solid Films 174, 217 (1989).

${ }^{52}$ T. Minami, MRS Bull. 25, 8 (2000).

${ }^{53}$ M. L. Addonizio, A. Antonaia, G. Cantele, and C. Privato, Thin Solid Films 349, 93 (1999).

${ }^{54}$ F. Ruske, V. Sittinger, W. Werner, B. Szyszka, K.-U. van Osten, K. Dietrich, and R. Rix, Surf. Coat. Technol. 200, 236 (2005).

${ }^{55}$ P. Sagar, M. Kumar, and R. M. Mehra, Thin Solid Films 489, 94 (2005). 